2

\section{Send It Up A Little Higher Joe.}

JIM STANFORD.
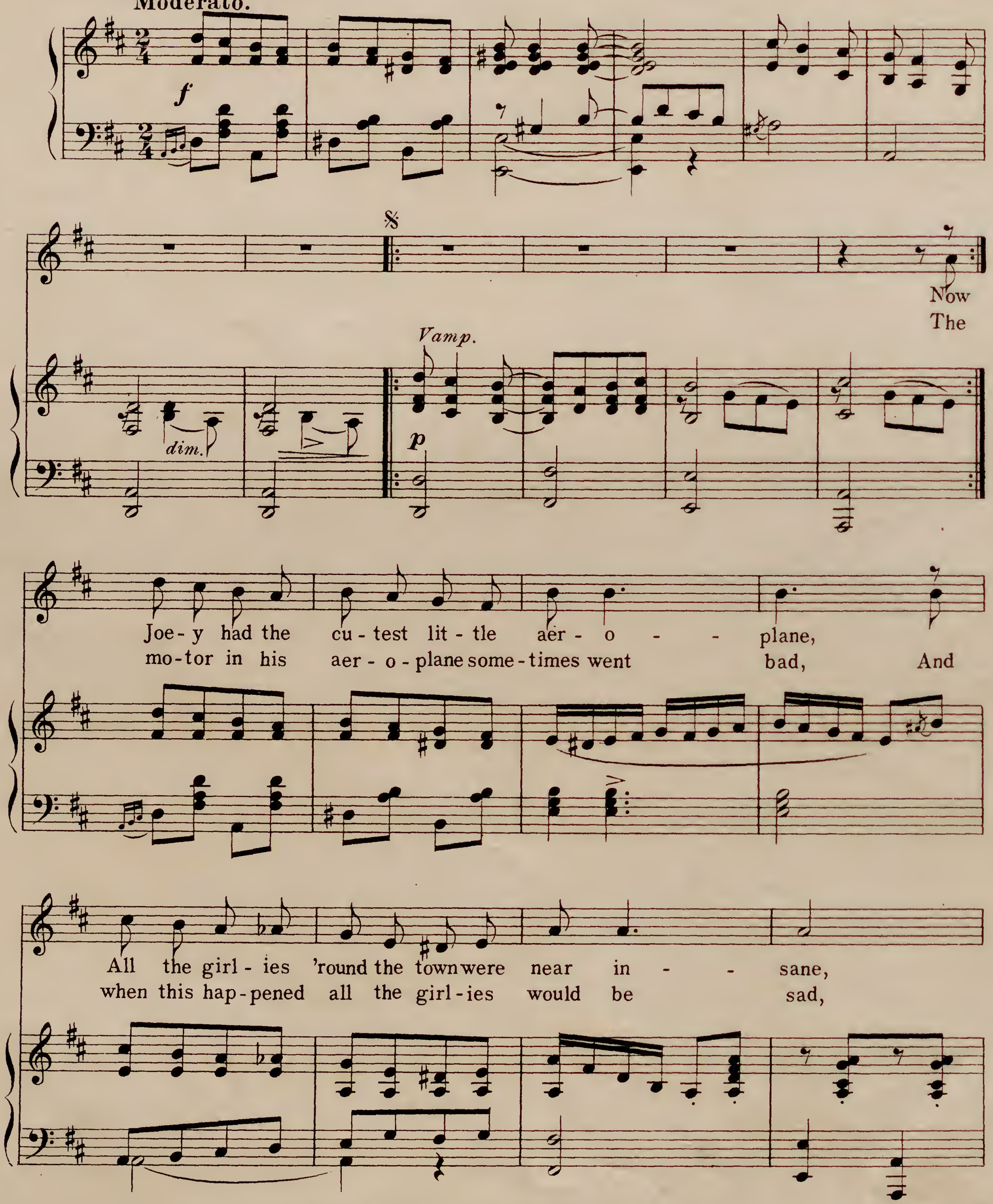

Copyright MCMXIV by Stanford Music Co. New Haven, Conn.

Copyright Canada MCMXIV by Stanford Music Co. 

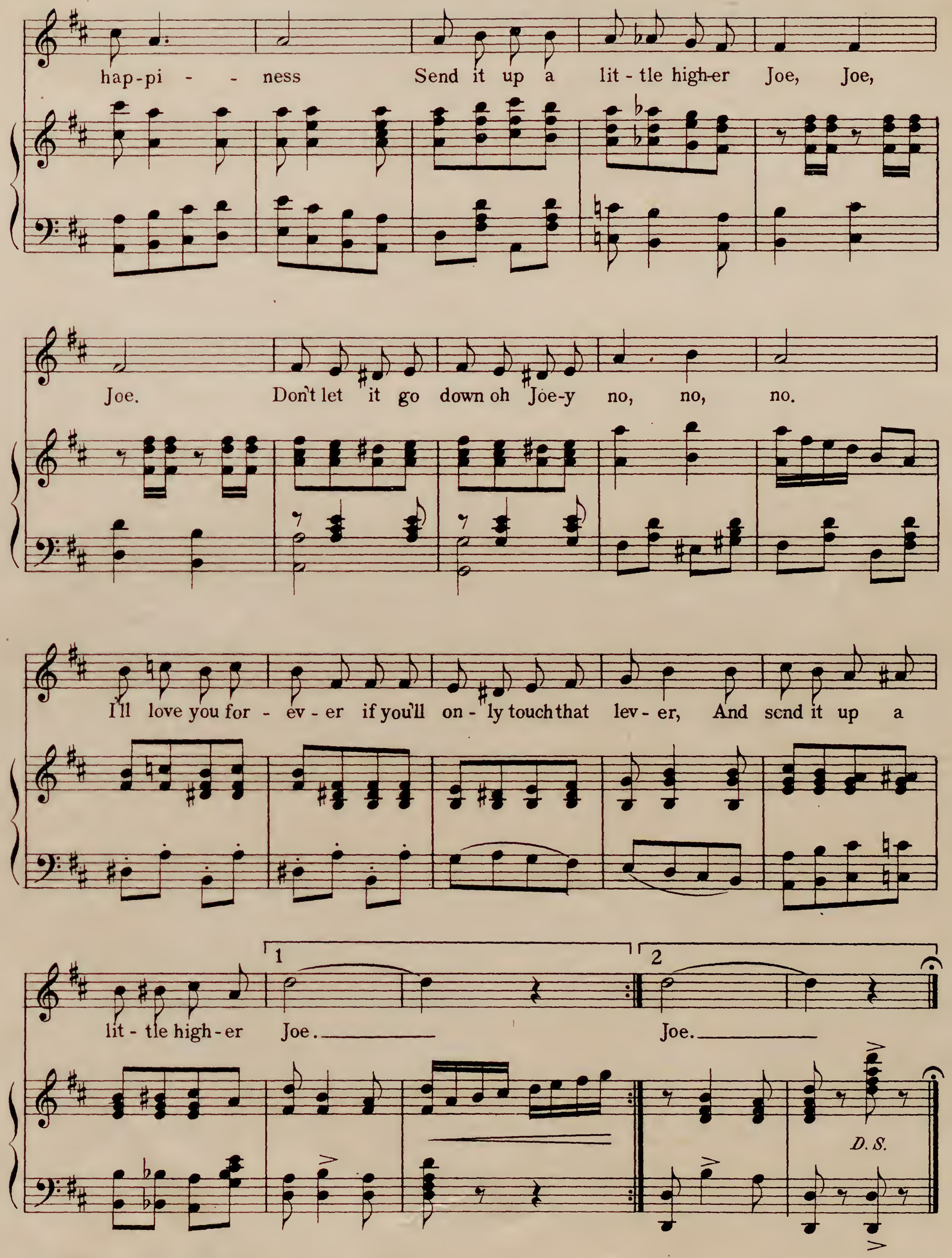


\section{TRY THESE ON YOUR PIANO}

Send It Up A Little Higher Joe.

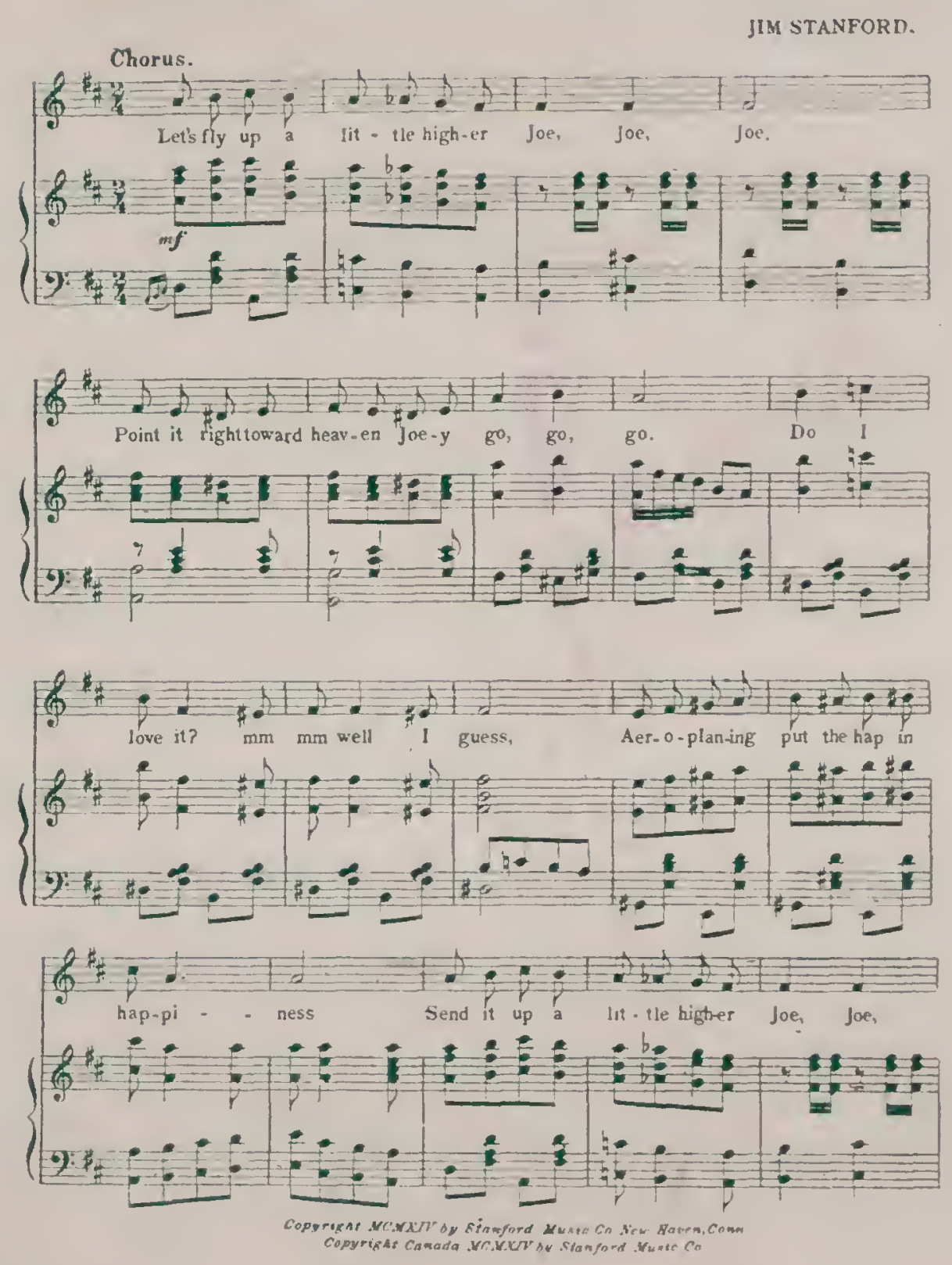

Where Do You Go From Here.
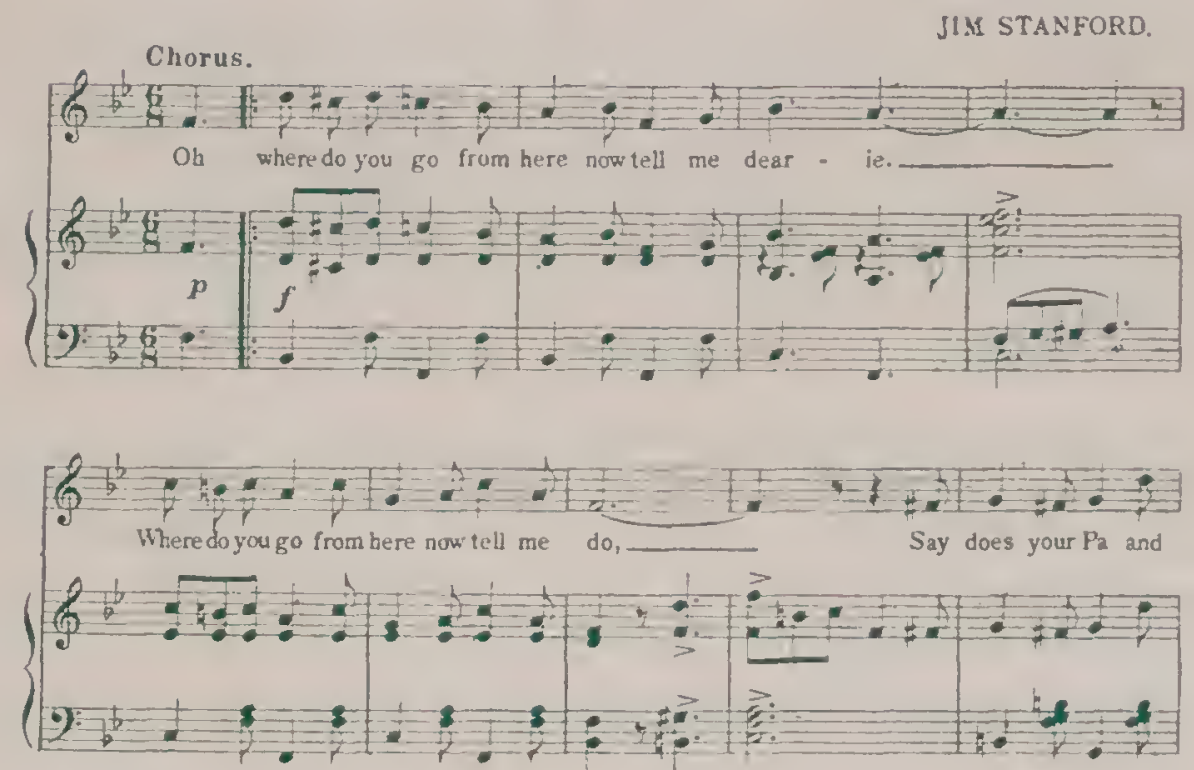

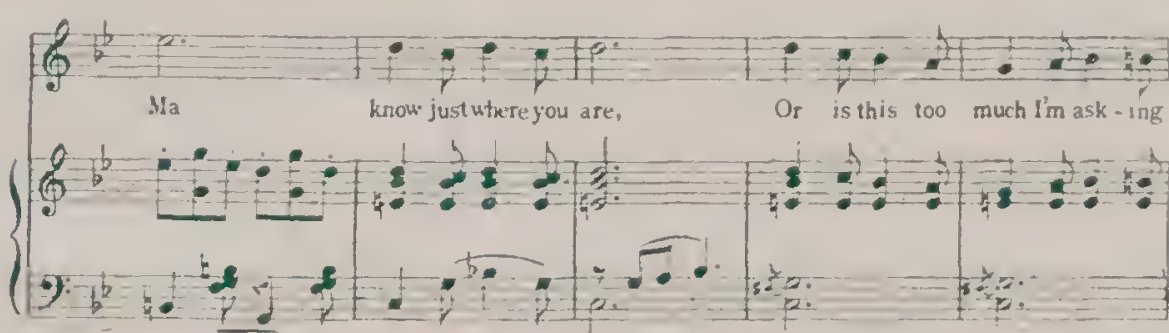

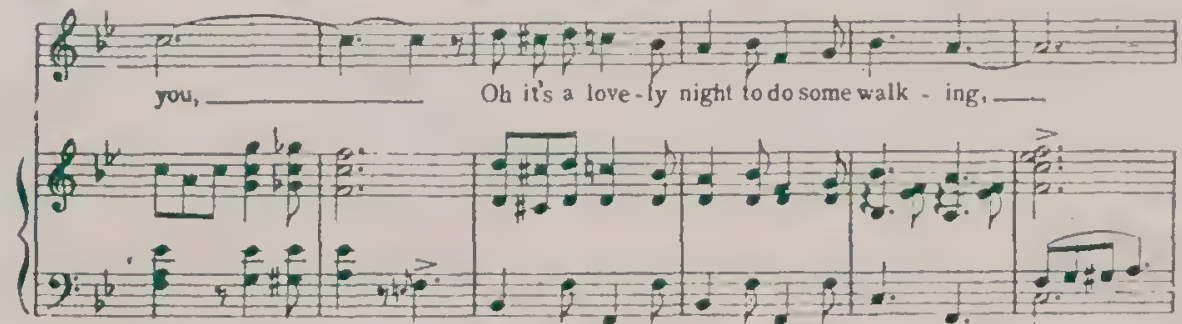

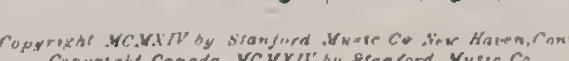

I'm Crazy'Bout It.
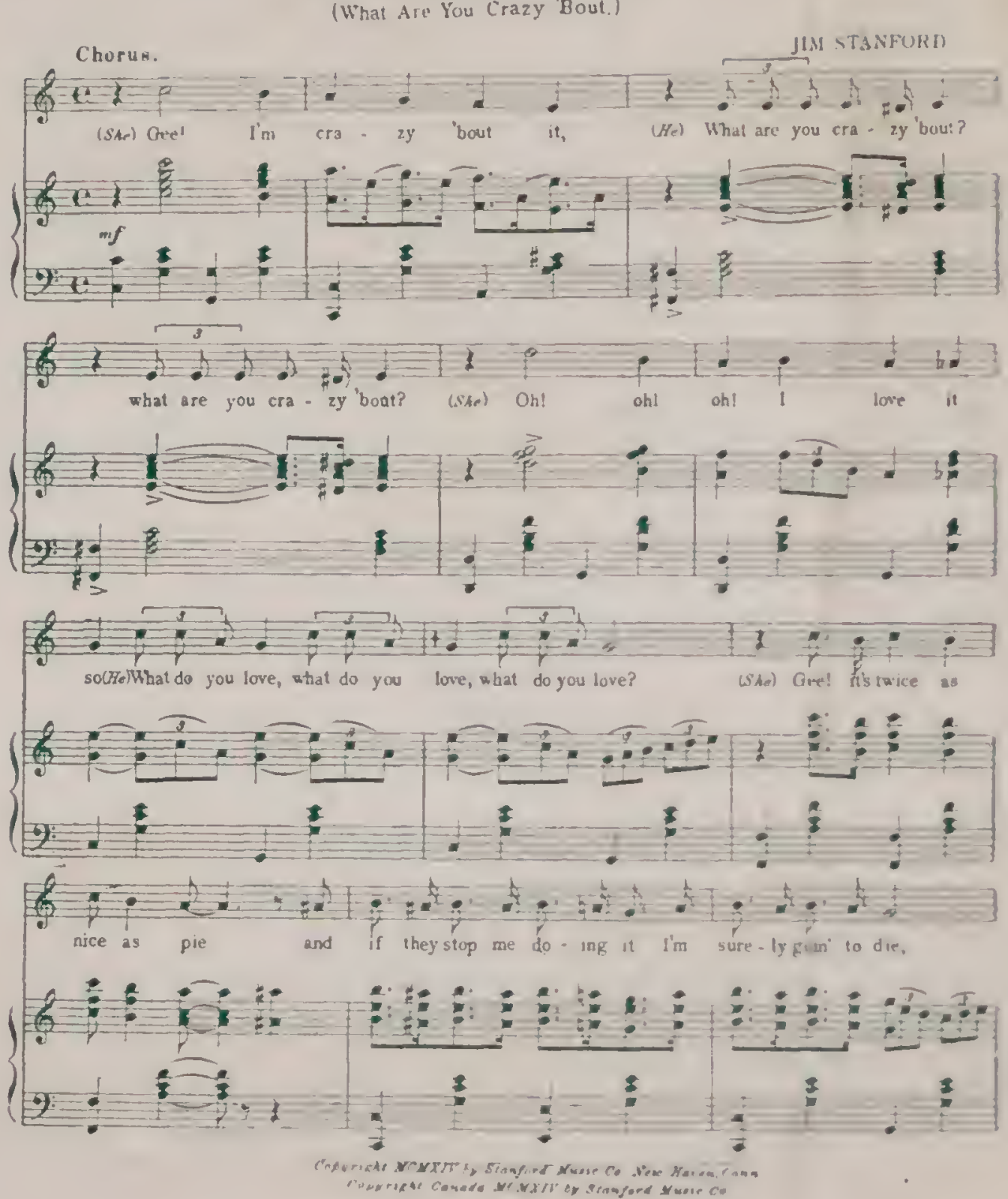

I've Given Many Kisses To Many Girls (But Not The Kind Sweetheart I Grve To You.)
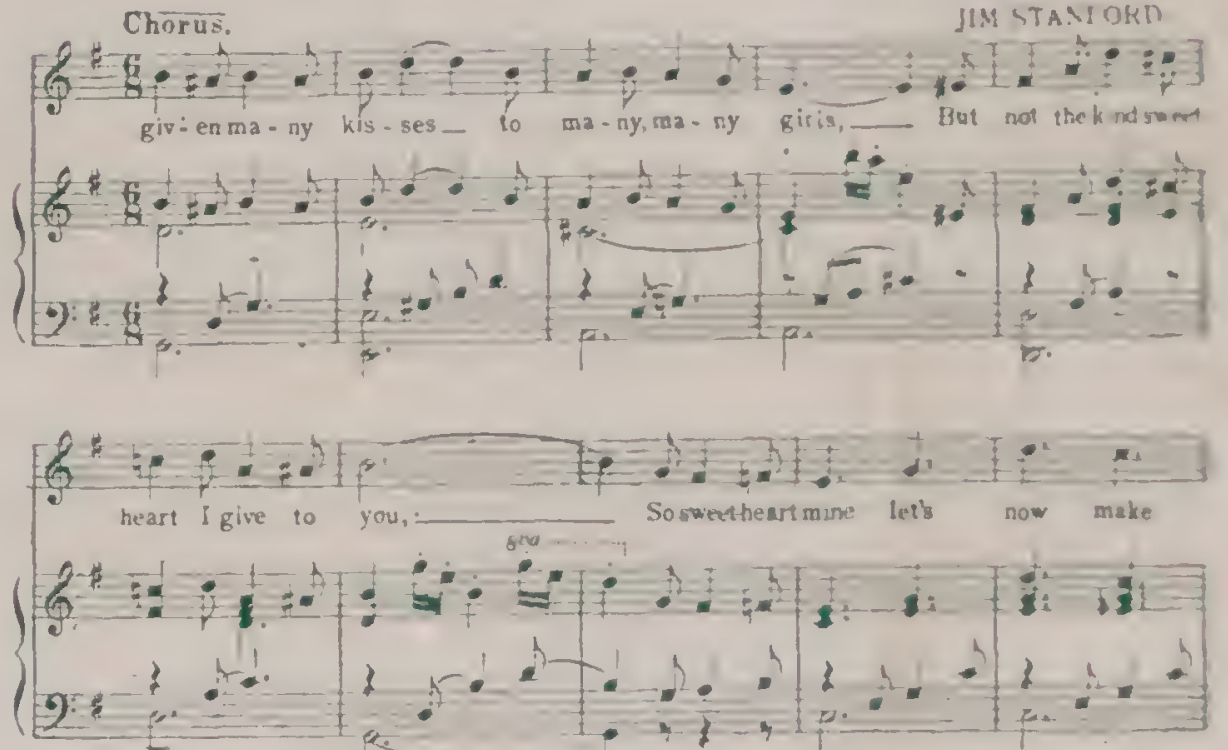

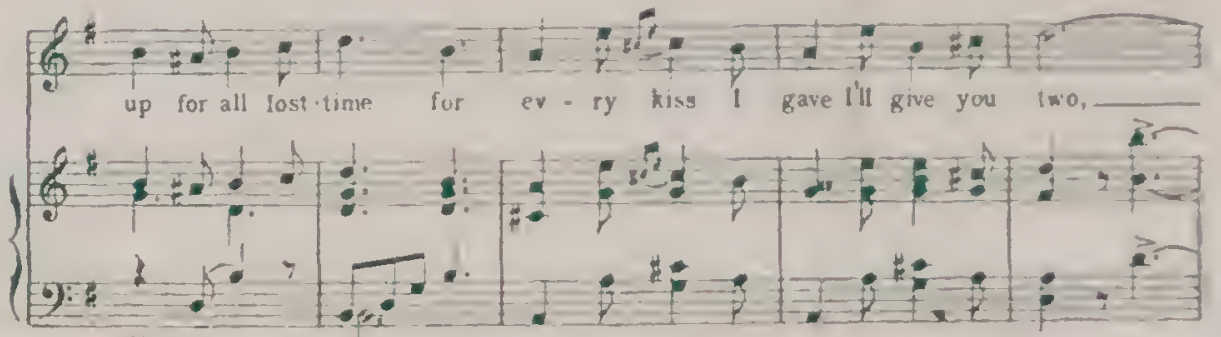

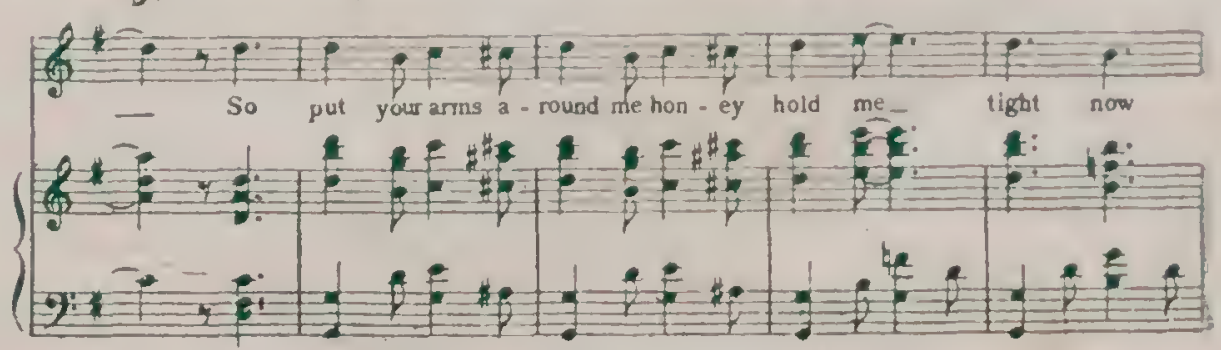

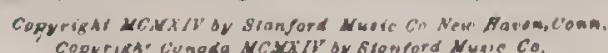

\section{FOR SALE BY ALL DEALERS!}

